\title{
Pengaruh kombinasi Superdisintegrant Crospovidone dan Croscarmellose Sodium pada sifat fisik dan disolusi Fast Disintegrating Tablet Hidroklorotiazid
}

\author{
The Effect of Superdisintegrant Combination of Crospovidone and \\ Croscarmellose Sodium on Physical Properties and Dissolution of Fast \\ Disintegrating Tablets Hydrochlorothiazide
}

\author{
Dewi Farahiyah"1, Teuku Nanda Saifullah Sulaiman ${ }^{2 *}$ \\ 1 Program S-1 Fakultas Farmasi Universitas Gadjah Mada, Yogyakarta \\ ${ }^{2}$ Laboratorium Teknologi Farmasi, Fakultas Farmasi, Universitas Gadjah Mada, Yogyakarta \\ Corresponding author: Teuku Nanda Saifullah Sulaiman: Email: tn_saifullah@ugm.ac.id \\ Submitted: 30-11-2020 Revised: 01-12-2020 \\ Accepted: 15-12-2020
}

\begin{abstract}
ABSTRAK
Hidroklorotiazid (HCT) merupakan obat lini pertama untuk penanganan hipertensi. HCT memiliki kelemahan terkait bioavailabilitasnya yang rendah dan umumnya tersedia dalam bentuk sediaan tablet konvensional sehingga dapat menimbulkan masalah tersendiri bagi pasien yang tidak mampu menelan tablet. Fast disintegrating tablet (FDT) HCT merupakan tablet yang dapat terdisintegrasi dan terdisolusi dengan cepat di dalam mulut yang memungkinkan obat dapat diabsorpsi di daerah pregastric sehingga meningkatkan bioavailabilitas obat. Penelitian ini bertujuan untuk mendapatkan formula FDT HCT yang menghasilkan sifat fisik optimum dengan kombinasi superdisintegrant crospovidone (CP) dan croscarmellose sodium (CCS). FDT HCT diformulasikan menggunakan kombinasi superdisintegrant CP:CCS pada rentang konsentrasi CP 2-6\% dan CCS 1-5\%. FDT dibuat dengan metode kempa langsung. Tablet FDT yang dihasilkan, dilakukan uji sifat fisik tablet yaitu kekerasan, kerapuhan, waktu disintegrasi, waktu pembasahan, rasio absorpsi air, dan uji disolusi. Data diolah dengan metode simplex lattice design menggunakan software Design Expert ${ }^{\circledR}$ untuk memprediksi formula optimum. Hasil penelitian menunjukkan bahwa CP berpengaruh signifikan dalam mempercepat waktu pembasahan, waktu disintegrasi, dan disolusi tablet, sedangkan CCS berpengaruh signifikan dalam menurunkan kekerasan, meningkatkan kerapuhan dan rasio absorpsi air.
\end{abstract}

Kata kunci: FDT; hidroklorotiazid; crospovidone; croscarmellose sodium

\section{ABSTRACT}

Hydrochlorothiazide (HCT) is one of the preferred pharmacological treatment for hypertension. HCT has a disadvantage due to its low bioavailability, and it is generally available in tablet dosage forms that can cause problems for same patients for using. Fast disintegrating tablet (FDT) HCT is a tablet that is disintegrated or dissolved rapidly in the mouth so that some drugs may be absorbed in the pregastric region and then, increase its solubility The aim of this study is to get a formula of FDT HCT with a combination of superdisintegrant crospovidone (CP) and croscarmellose sodium (CCS) that can produce tablets with optimum physical properties. FDT HCT was formulated using a combination of superdisintegrant CP: CCS at a range concentration of $2-6 \%$ CP and $1-5 \%$ CCS. FDT was prepared by direct compression. FDT tablets were manufactured, tested for physical properties such as hardness, friability, disintegration time, wetting time, water absorption ratio, and dissolution. Data from different parameters were processed with simplex lattice design method using Design Expert ${ }^{\circledR}$ software to predict an optimum formula. The results showed that CP had a significant effect in increasing wetting time, disintegration time, and dissolution of tablets, while CCS had a significant effect in reducing hardness, increasing friability and water absorption ratio.

Keywords: FDT; hydrochlorothiazide; crospovidone; croscarmellose sodium 


\section{PENDAHULUAN}

Hidroklorotiazid (HCT) merupakan obat golongan diuretik tiazid yang umumnya digunakan sebagai lini pertama untuk penanganan hipertensi (DepKes RI, 2006). Obat ini bekerja pada ginjal dengan meningkatkan ekskresi air dan natrium sehingga curah jantung berkurang. Hal ini menyebabkan tekanan darah menjadi turun (Nugroho, 2012). Penggunaan HCT sebagai antihipertensi memiliki kelemahan, yaitu bioavailabilitas yang rendah sekitar 65-70\% (Moffat dkk., 2011). HCT umumnya tersedia dalam bentuk sediaan tablet konvensional. Bentuk sediaan ini dapat menimbulkan permasalahan bagi pasien yang memiliki kesulitan menelan tablet. Salah satu solusi yang dapat dilakukan, yaitu memformulasikan HCT dalam bentuk sediaan fast disintegrating tablet (FDT).

FDT merupakan sediaan tablet yang didesain untuk terdisintegrasi dalam waktu kurang dari 1 menit ketika kontak dengan cairan saliva yang terbatas (Allen dkk., 2011). Tablet yang terdisintegrasi cepat di dalam mulut akan segera melepaskan zat aktifnya. Zat aktif selanjutnya akan melarut atau terdispersi dalam cairan saliva. Selain itu, sejumlah bagian obat ada yang dapat diabsorpsi di daerah pregastric seperti mulut, faring, dan esofagus ketika saliva turun ke lambung sehingga dapat meningkatkan bioavailabilitas obat (Bhowmik dkk., 2009). FDT juga menawarkan kemudahan dalam penggunaannya, khususnya untuk pasien yang mengalami disfagia. Tablet cukup diletakkan di atas lidah yang akan segera hancur menjadi bentuk granul kecil kemudian melarut dalam saliva sehingga mudah ditelan (Fu dkk., 2004). Formulasi FDT dapat dilakukan dengan penambahan superdisintegrant yang dapat memfasilitasi hancurnya matriks tablet dengan cepat. Dalam penelitian ini digunakan superdisintegrant crospovidone (CP) dan croscarmellose sodium (CCS).

$\mathrm{CP}$ sebagai bahan penghancur mempunyai mekanisme utama, yaitu penyerapan air (water wicking). Hal ini disebabkan struktur partikelnya yang sangat berpori sehingga dapat dengan cepat mengabsorpsi medium ke dalam tablet melalui aksi kapiler dan mempercepat waktu pembasahan. Selain itu, CP menunjukkan kompaktibilitas dan kompresibilitas yang lebih baik dibandingkan dengan CCS (Battu dkk., 2007; Gohel dkk., 2007).

CCS sebagai bahan penghancur mempunyai mekanisme utama, yaitu pengembangan (swelling). CCS dapat mengembang 4-8 kali dari ukuran semula sehingga tablet dapat cepat terdisintegrasi (Guest, 2009). CCS konsentrasi 2\% sudah dapat menghasilkan waktu disintegrasi yang optimum, sedangkan CP pada konsentrasi 5\% (Zhang dkk., 2010).

Penggabungan mekanisme dari CP dan CCS dapat meningkatkan kecepatan disintegrasi dan memperbaiki sifat fisik FDT HCT. Penelitian ini dilakukan untuk melihat pengaruh penggunaan superdisintegrant $\mathrm{CP}$ dan CCS terhadap sifat fisik dan disolusi tablet yang dihasilkan. Selain itu juga untuk mengoptimasi formula FDT HCT dengan menggunakan kombinasi superdisintegrant CP dan CCS sehingga dihasilkan formula optimum.

\section{METODOLOGI}

\section{Bahan}

Hidroklorotiazid (Changzhou-Pharma), Crospovidone (BASF), Croscarmellose sodium (JRS Pharma), Microcrystalline cellulose PH 102 (Asahi KASEI), Tropicana Slim ${ }^{\circledR}$ (PT. Nutrifood Indonesia), Manitol (Cargill Inc.), PEG 6000 (Clariant), dan Cab-O-Sil ${ }^{\circledR}$ (Wacker Chemicals). zat warna FDC Strawberry Red, akuades, dan dapar fosfat $\mathrm{pH}$ 6,8. Semua bahan merupakan pharmaceutical grade.

\section{Alat}

Cube mixer Erweka ${ }^{\circledR}$ (Jerman), Mesin tablet single punch (Korch tipe PE 246 SRC, Jerman), Alat uji kekerasan Stokes Mosanto ${ }^{\circledR}$ Tablet Hardness Tester, Alat uji disolusi (Erweka ${ }^{\circledR}$ tipe DT-700, Jerman), Alat uji kerapuhan Erweka ${ }^{\circledR}$ friabilator abbrasive tester (Erweka ${ }^{\circledR}$ tipe TA-10/TA-20., Jerman), dan Spektrofotometer Genesys ${ }^{\circledR}$.

\section{Jalannya penelitian \\ Pembuatan sediaan fast disintegrating tablet FDT HCT dibuat dengan metode kempa langsung dengan formula seperti tercantum pada Tabel I. HCT dan MCC PH 102 dimasukkan ke dalam cube mixer kemudian dilakukan homogenisasi dengan kecepatan $40 \mathrm{rpm}$ selama 10 menit. Crospovidone, croscarmellose sodium,}


Tabel I. Formula fast disintegrating tablet hidroklorotiazid

\begin{tabular}{lccccc}
\hline Bahan (mg) & Run 1 & Run 2 & Run 3 & Run 4 & Run 5 \\
\hline Hidroklorotiazid & 12,5 & 12,5 & 12,5 & 12,5 & 12,5 \\
Crospovidone & 9 & 6 & 7,5 & 3 & 4,5 \\
Croscarmellose sodium & 1,5 & 4,5 & 3 & 7,5 & 6 \\
MCC PH 102 & 82,5 & 82,5 & 82,5 & 82,5 & 82,5 \\
Manitol & 11 & 11 & 11 & 11 & 11 \\
Tropicana Slim $^{\circledR}$ & 24 & 24 & 24 & 24 & 24 \\
Cab-O-Sil $^{\circledR}$ & 1,5 & 1,5 & 1,5 & 1,5 & 1,5 \\
PEG 6000 & 8 & 8 & 8 & 8 & 8 \\
Total & $\mathbf{1 5 0}$ & $\mathbf{1 5 0}$ & $\mathbf{1 5 0}$ & $\mathbf{1 5 0}$ & $\mathbf{1 5 0}$ \\
\hline
\end{tabular}

manitol, Tropicana $\quad$ Slim $^{\circledR}$ dan $\quad$ Cab-O-Sil ${ }^{\circledR}$ kemudian ditambahkan dan dihomogenisasi selama 5 menit. Selanjutnya ditambahkan PEG 6000 dan terakhir dilakukan homogenisasi lagi dengan kecepatan $40 \mathrm{rpm}$ selama 5 menit. Campuran bahan kemudian dikempa menggunakan mesin tablet single punch dengan ukuran dies $7 \mathrm{~mm}$.

\section{Pengujian sifat alir campuran bahan}

Sebelum dikempa, campuran bahan diuji sifat alirnya dengan metode sudut diam. Sejumlah 100 gram bahan ditimbang, kemudian dituangkan secara perlahan-lahan ke dalam corong pengukur yang tertutup bagian bawahnya. Penutup corong selanjutnya dibuka dan bahan dibiarkan mengalir. Pengukuran sudut diam dilakukan dengan mengamati tinggi dan diameter kerucut yang terbentuk.

\section{Pengujian sifat fisik fast disintegrating tablet} Tablet yang dihasilkan kemudian dilakukan pengujian sifat fisik, meliputi kekerasan, kerapuhan, waktu disintegrasi, waktu pembasahan, rasio absorpsi air, dan uji disolusi.

\section{Kekerasan}

Uji kekerasan dilakukan menggunakan alat uji kekerasan Mosanto ${ }^{\circledR}$ Tablet Hardness Tester dengan mengambil 6 tablet dari masingmasing formula. Sebuah tablet diletakkan secara vertikal dan tegal lurus terhadap tuas yang telah diatur pada skala nol sebelum pengujian. Ulir diputar sehingga tablet akan terjepit dan tertekan semakin kuat hingga pada akhirnya tablet pecah. Besarnya tekanan tersebut dibaca dan dicatat sebagai kekerasan tablet.
Kerapuhan

Uji kerapuhan dilakukan menggunakan alat uji kerapuhan Erweka ${ }^{\circledR}$ friability tester. Dua puluh tablet dibebasdebukan dan ditimbang terlebih dahulu untuk mengetahui bobot awal. Tablet tersebut selanjutnya dimasukkan ke dalam friabilator dan diputar sebanyak 100 putaran (4 menit) atau $25 \mathrm{rpm}$. Tablet selanjutnya ditimbang kembali dan dihitung persentase kehilangan bobot sebelum dan sesudah perlakuan.

\section{Waktu disintegrasi}

Uji waktu disintegrasi dilakukan dengan cara mengadaptasi dan memodifikasi prosedur yang dilakukan oleh Vaghela dkk. (2011). FDT ditempatkan pada cawan petri berdiameter 5 $\mathrm{cm}$ yang sudah berisi air $20 \mathrm{~mL}$. Waktu disintegrasi yang diperlukan oleh 6 tablet dicatat kemudian dihitung reratanya.

\section{Waktu pembasahan}

Penentuan uji waktu pembasahan dilakukan dengan mengadaptasi dan memodifikasi prosedur yang dilakukan oleh Bhowmik dkk. (2009). Uji ini dilakukan dengan cara meletakkan 5 lembar kertas tisu ke dalam cawan petri berdiameter $10 \mathrm{~cm}$ yang sebelumnya telah diisi $10 \mathrm{~mL}$ akuades yang mengandung zat warna merah. Sebuah tablet kemudian diletakkan di atas kertas tisu tersebut secara perlahan. Waktu yang diperlukan untuk menimbulkan warna merah di seluruh permukaan tablet dihitung sebagai waktu pembasahan.

\section{Rasio absorpsi air}

Penentuan rasio absorpsi air dilakukan dengan menggunakan serangkaian alat uji daya 
Tabel II. Hasil uji sifat dan disolusi fast disintegrating tablet hidroklorotiazid (rata-rata \pm SD)

\begin{tabular}{|c|c|c|c|c|c|c|c|}
\hline Formula & $\begin{array}{c}\text { Sudut } \\
\operatorname{diam}\left({ }^{\circ}\right)\end{array}$ & $\begin{array}{c}\text { Kekerasan } \\
\left(\mathrm{kg} / \mathrm{cm}^{2}\right)\end{array}$ & $\begin{array}{c}\text { Kerapuhan } \\
(\%)\end{array}$ & $\begin{array}{c}\text { Waktu } \\
\text { disintegrasi } \\
\text { (detik) }\end{array}$ & $\begin{array}{c}\text { Waktu } \\
\text { pembasahan } \\
\text { (detik) }\end{array}$ & $\begin{array}{c}\text { Rasio } \\
\text { absorpsi } \\
\text { air (\%) }\end{array}$ & $Q_{15}(\%)$ \\
\hline Run 1 & $\begin{array}{c}28,07 \pm \\
0,52\end{array}$ & $\begin{array}{c}4,62 \pm \\
0,14\end{array}$ & $\begin{array}{c}0,24 \pm \\
0,00\end{array}$ & $\begin{array}{l}9,02 \pm \\
0,41\end{array}$ & $8,94 \pm 0,30$ & $\begin{array}{c}63,08 \pm \\
2,11\end{array}$ & $\begin{array}{r}89,13 \\
\pm 2,11\end{array}$ \\
\hline Run 2 & $\begin{array}{c}28,07 \pm \\
0,52\end{array}$ & $\begin{array}{c}4,50 \pm \\
0,23\end{array}$ & $\begin{array}{c}0,25 \pm \\
0,02\end{array}$ & $\begin{array}{c}11,70 \pm \\
0,83\end{array}$ & $10,10 \pm 0,61$ & $\begin{array}{c}65,38 \pm \\
0,69\end{array}$ & $\begin{array}{l}87,27 \\
\pm 2,31\end{array}$ \\
\hline Run 3 & $\begin{array}{c}27,77 \pm \\
0,52\end{array}$ & $\begin{array}{c}4,53 \pm \\
0,09\end{array}$ & $\begin{array}{c}0,26 \pm \\
0,02\end{array}$ & $\begin{array}{c}10,27 \pm \\
0,33\end{array}$ & $9,96 \pm 0,71$ & $\begin{array}{c}64,59 \pm \\
1,76\end{array}$ & $\begin{array}{r}88,44 \\
\pm 2,23\end{array}$ \\
\hline Run 3 & $\begin{array}{c}27,47 \pm \\
0,00\end{array}$ & $\begin{array}{c}4,15 \pm \\
0,09\end{array}$ & $\begin{array}{c}0,32 \pm \\
0,10\end{array}$ & $\begin{array}{c}18,83 \pm \\
0,46\end{array}$ & $16,28 \pm 0,99$ & $\begin{array}{c}68,57 \pm \\
0,68\end{array}$ & $\begin{array}{r}88,73 \\
\pm 4,73\end{array}$ \\
\hline Run 5 & $\begin{array}{c}27,17 \pm \\
0,52 \\
\end{array}$ & $\begin{array}{c}4,06 \pm \\
0,12 \\
\end{array}$ & $\begin{array}{c}0,29 \pm \\
0,07 \\
\end{array}$ & $\begin{array}{c}16,94 \pm \\
0,28\end{array}$ & $14,09 \pm 1,08$ & $\begin{array}{c}66,14 \pm \\
1,17 \\
\end{array}$ & $\begin{array}{r}88,48 \\
\pm 3,33 \\
\end{array}$ \\
\hline
\end{tabular}

serap. Tablet diletakkan di atas kertas saring yang telah dijenuhkan pada daerah A. Tablet akan menyerap air yang berarti air pada botol penampung di atas neraca analitik (daerah B) berkurang. Berkurangnya bobot air di atas neraca analitik inilah yang nantinya dihitung sebagai bobot air yang diserap tablet (Soebagyo dkk., 2013).

\section{Uji disolusi}

Uji disolusi FDT secara in vitro didasarkan pada metode yang terdapat pada USP apparatus 2 (paddle type) dengan kecepatan putar pengaduk $50 \mathrm{rpm}$ dalam 900 $\mathrm{mL}$ medium disolusi (dapar fosfat $\mathrm{pH} 6,8$ ) , temperatur $37 \pm 0,5^{\circ} \mathrm{C}$. Uji dilakukan selama 15 menit dengan rentang pengambilan sampel sebanyak $10 \mathrm{~mL}$ pada menit ke-1, 3, 5, 10, dan 15 menit. Setiap kali pengambilan pada masingmasing interval waktu pengambilan, media disolusi diganti dengan media disolusi baru sebanyak $10 \mathrm{~mL}$. Sampel yang diambil kemudian disaring dan diukur serapannya pada panjang gelombang maksimal dan diplotkan pada kurva baku untuk mendapatkan kadar HCT terukur.

\section{Analisis Hasil}

Analisis data untuk memperoleh formula optimum yang memberikan respon sifat fisik optimum dilakukan dengan menggunakan software Design Expert ${ }^{\circledR}$ version 9.0.3.1 (trial) dengan metode simplex lattice design. Data respon hasil uji sifat fisik tablet dari kelima formula kemudian dimasukkan ke dalam program sehingga diperoleh grafik 2 dimensi dan didapatkan persamaan SLD untuk masing-masing sifat fisik. Grafik dari Numerical Optimization akan menunjukkan point prediction yang merupakan formula optimum terpilih.

\section{HASIL DAN PEMBAHASAN}

Hasil uji sifat fisik tablet dan disolusi tercantum pada Tabel II. Sediaan FDT ini dibuat dengan metode kempa langsung, salah satu persyaratan material untuk dapat dikempa langsung adalah campuran bahan tersebut dapat mengalir dengan baik (sifat alirnya baik). Menurut British Pharmacopoeia (2014), granul yang memiliki sudut diam antara 25-30 derajat dikatakan memiliki sifat alir yang sangat baik. Data dari Tabel II menunjukkan kelima run memiliki sudut diam antara 25-30 sehingga memenuhi persyaratan sifat alir yang baik untuk kempa langsung.

Tablet dalam penelitian ini dikempa dengan penurunan punch atas yang sama (tekanannya sama) agar dapat memberi gambaran bagaimana pengaruh bahan penghancur pada kekerasan dan juga waktu hancur serta disolusi. Hasil uji kekerasan pada Tabel II menunjukkan bahwa tablet FDT memiliki kekerasan sekitar 3-5 kg/ $\mathrm{cm}^{2}$.

Dari data Tabel II, selanjutnya dianalisis dengan software design expert untuk melihat pengaruh superdisintegrant terhadap sifat fisik dan disolusi. Contour plot yang dihasilkan tercantum pada Gambar 1.

Contour plot untuk respon kekerasan berupa garis yang linear, dengan persamaan seperti tercantum pada Tabel III. 

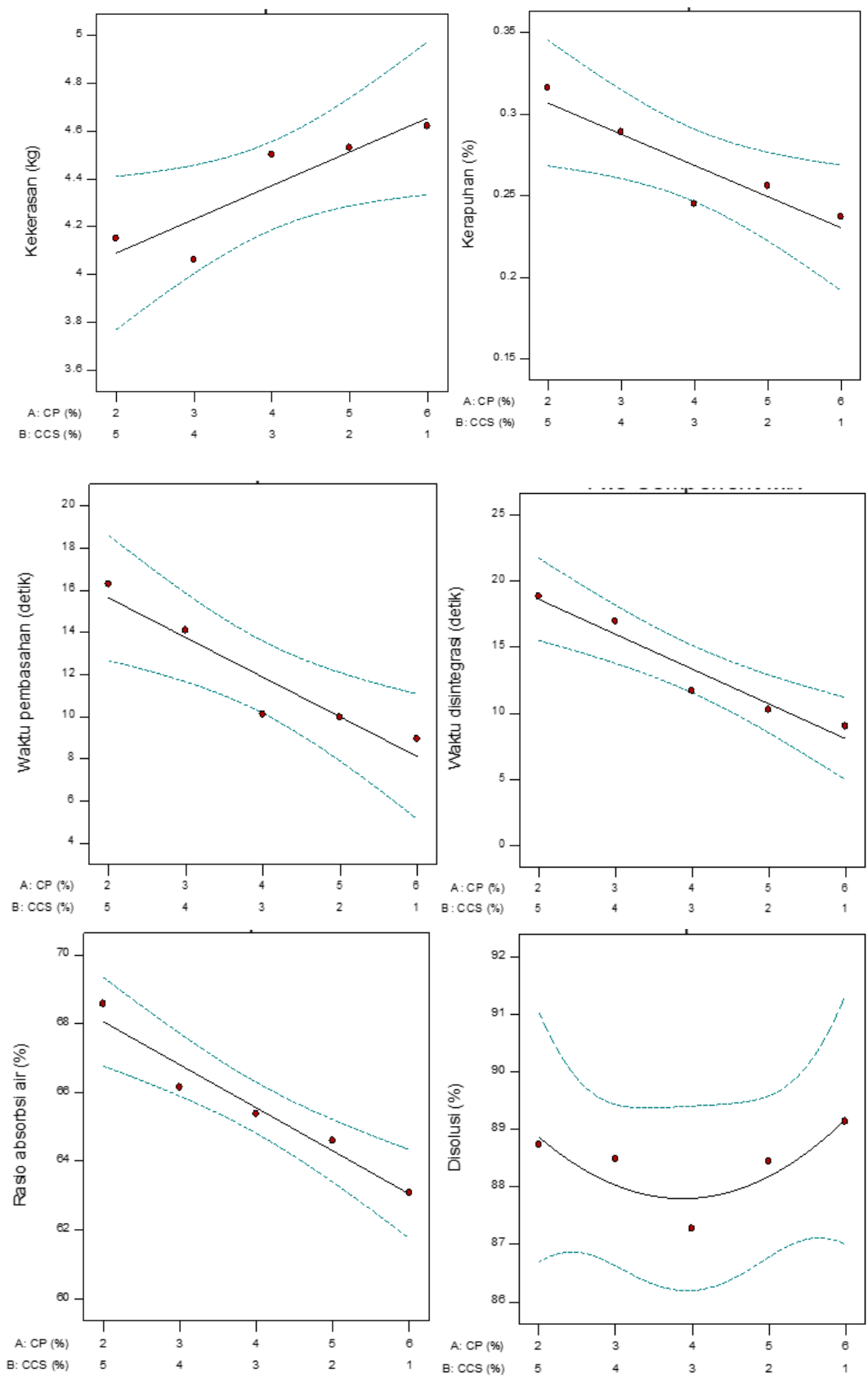

Gambar 1. Grafik SLD respon uji kekerasan, kerapuhan, waktu pembasahan, rasio absorbsi air, waktu disintegrasi dan disolusi FDT hidroklorotiazid

Dari persamaan tersebut dapat disimpulkan bahwa peningkatan proporsi CP dan CCS berbanding lurus dengan peningkatan kekerasan. Nilai koefisien CP $(0,69)$ lebih besar dari CCS $(0,54)$, sehingga pengaruh CP lebih besar dalam meningkatkan respon nilai kekerasan dibandingkan CCS. Menurut penelitian yang dilakukan Gohel dkk. (2007), CP memiliki kompaktibilitas dan kompresibilitas yang lebih baik dibandingkan CCS sehingga ketika dikempa dengan tekanan kompresi yang sama, CP akan menghasilkan tablet dengan nilai kekerasan yang lebih tinggi dibandingkan CCS. Hasil uji kerapuhan menunjukkan hasil yang selaras dengan hasil uji kekerasan tablet, semakin tinggi kekerasan, semakin rendah 
Tabel III. Persamaan berdasarkan simplex lattice design untuk berbagai respon uji sifat fisik tablet FDT hidroklorotiazid

\begin{tabular}{ll}
\hline \multicolumn{1}{c}{ Parameter } & Persamaan \\
\hline Kekerasan & $\mathrm{Y}=0,69(\mathrm{~A})+0,54(\mathrm{~B})$ \\
Kerapuhan & $\mathrm{Y}=0,03(\mathrm{~A})+0,05(\mathrm{~B})$ \\
Waktu pembasahan & $\mathrm{Y}=0,89(\mathrm{~A})+2,77(\mathrm{~B})$ \\
Rasio absorbsi air & $\mathrm{Y}=8,83(\mathrm{~A})+10,08(\mathrm{~B})$ \\
Waktu disintegrasi & $\mathrm{Y}=0,78(\mathrm{~A})+3,41(\mathrm{~B})$ \\
Disolusi & $\mathrm{Y}=12,97(\mathrm{~A})+13,20(\mathrm{~B})-0,30(\mathrm{~A})(\mathrm{B})$ \\
\hline
\end{tabular}

kerapuhan. Contour plot respon uji kerapuhan (Gambar 1) menunjukkan pola yang linier. Proporsi CP yang meningkat akan menghasilkan tablet dengan nilai kerapuhan yang semakin rendah. Semua formula memenuhi persyaratan kerapuhan tablet pada batas yang diperbolehkan $(<1 \%)$. Persamaan yang diperoleh $Y=0,03(\mathrm{~A})+0,05(\mathrm{~B})$. Hal ini menunjukkan bahwa CP dan CCS memberikan pengaruh positif dalam meningkatkan kerapuhan tablet, dengan nilai koefisien CCS lebih besar dari CP. CCS memiliki kompaktibilitas yang kurang baik sehingga tablet yang dihasilkan kurang mampat ketika mendapatkan tekanan (Gohel dkk., 2007) dan menyebabkan ikatan antarpartikel lemah sehingga tablet menjadi rapuh.

Waktu disintegrasi tablet merupakan waktu yang diperlukan tablet untuk hancur menjadi granul atau partikel-partikel penyusunnya yang lebih halus ketika terjadi kontak dengan cairan. Department of Health (2014) dalam British Pharmacopoeia mensyaratkan waktu disintegrasi FDT tidak lebih dari 3 menit. Hasil uji waktu disintegrasi pada Tabel II menunjukkan bahwa kelima formula memenuhi persyaratan waktu disintegrasi FDT. Grafik SLD respon uji waktu disintegrasi yang ditampilkan pada Gambar 1 menunjukkan pola yang linier. Proporsi CP yang semakin tinggi dalam kombinasi superdisintegrant CP-CCS akan menghasilkan tablet dengan waktu disintegrasi yang semakin cepat.

Persamaan simplex lattice design yang diperoleh untuk respon waktu disintegrasi seperti tercantum pada Tabel III. Persamaan ini menunjukkan bahwa CCS dapat memperlama waktu disintegrasi dengan nilai koefisien sebesar 3,41. CCS memiliki kompaktibilitas yang kurang baik (Gohel dkk., 2007) sehingga penggunaannya pada konsentrasi yang tinggi akan menghasilkan tablet yang kurang mampat ketika mendapat tekanan. Hal ini menyebabkan tablet memiliki struktur pori yang besar dan banyak. Struktur pori yang besar akan mengurangi efektifitas disintegrasi tablet oleh superdisintegrant yang memiliki mekanisme utama swelling karena pendesakan yang yang terjadi tidak cukup kuat untuk mendesak partikel lainnya (Schiermeier dan Schmidt, 2002; Sulaiman, 2007).

Waktu pembasahan tablet merupakan waktu yang diperlukan untuk membasahi seluruh permukaan tablet. Parameter waktu pembasahan digunakan untuk mengetahui seberapa cepat FDT dapat menyerap air, kecepatan penyerapan air ini akan mempengaruhi kecepatan disintegrasi tablet. Hasil uji waktu pembasahan ditunjukkan pada Tabel II. Semakin cepat waktu pembasahan akan semakin baik karena dapat mempercepat waktu disintegrasi tablet (Gohel dkk., 2007). Grafik SLD respon uji waktu pembasahan (Gambar 1) menunjukkan pola yang linier. Proporsi CP yang semakin tinggi dalam kombinasi, akan menghasilkan tablet dengan waktu pembasahan yang semakin cepat. Persamaan simplex lattice design yang diperoleh untuk respon wakstu pembasahan adalah $\mathrm{Y}=0,89(\mathrm{~A})+2,77(\mathrm{~B})$. Persamaan ini menunjukkan bahwa CCS dapat memperlama waktu pembasahan dengan nilai koefisien sebesar 2,77 (lebih kecil dibandingkan CP). Hal ini karena CCS ketika kontak dengan air dapat mengembang dengan cepat (4-8 kali dari ukuran semula), sehingga volume tablet menjadi semakin besar dan semakin lama waktu yang dibutuhkan untuk membasahi seluruh permukaan tablet.

Hasil uji rasio absorpsi air ditunjukkan pada Tabel II. Grafik SLD respon uji rasio 


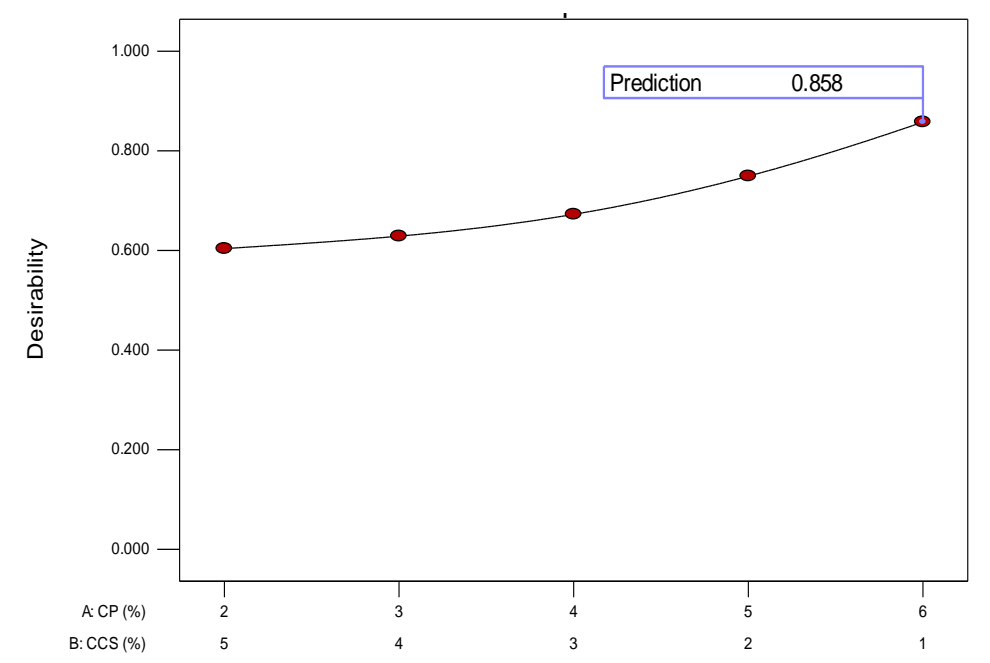

Gambar 2. Grafik contour plot untuk prediksi formula optimum

Tabel IV. Pemberian nilai dan bobot tiap parameter

\begin{tabular}{llccc}
\hline \multicolumn{1}{c}{ Respon } & Goal & Lower & Upper & Importance \\
\hline Kekerasan & in range & $3 \mathrm{~kg} / \mathrm{cm}^{2}$ & $5 \mathrm{~kg} / \mathrm{cm}^{2}$ & - \\
Kerapuhan & minimize & $0,10 \%$ & $0,90 \%$ & +++ \\
Waktu disintegrasi & minimize & $5 \mathrm{detik}$ & $30 \mathrm{detik}$ & +++++ \\
Waktu pembasahan & minimize & $5 \mathrm{detik}$ & $30 \mathrm{detik}$ & ++++ \\
Disolusi & maximize & $85 \%$ & $90 \%$ & ++++ \\
\hline
\end{tabular}

Keterngan $:$ maximize = nilai respon yang diinginkan mendekati titik maksimum (upper); minimize = nilai respon yang diinginkan mendekati titik minimum (lower)

absorpsi air yang ditampilkan pada Gambar 1 menunjukkan pola yang linier. Proporsi CCS yang semakin tinggi dalam kombinasi superdisintegrant CP-CCS akan menghasilkan tablet dengan rasio absorpsi air yang semakin besar. Persamaan simplex lattice design yang diperoleh untuk respon rasio absorpsi air adalah $\mathrm{Y}=8,83(\mathrm{~A})+10,08(\mathrm{~B})$. Persamaan ini menunjukkan bahwa CP dan CCS memberikan pengaruh positif dalam meningkatkan respon rasio absorpsi air dengan nilai koefisien CCS lebih besar dari CP sehingga memberikan pengaruh yang lebih besar dalam meningkatkan respon rasio absorpsi air. CCS memiliki struktur yang berserabut. Setiap serabutnya dapat berperan sebagai saluran hidrofilik (hydrophilic channels) untuk memfasilitasi water uptake ke dalam matriks tablet (Zhao dan Augsburger, 2005). Kenaikan rasio absorpsi air disebabkan karena kapasitas water uptake yang semakin tinggi seiring dengan bertambahnya konsentrasi CCS (Battu dkk., 2007).
WHO (2005) menyebutkan bahwa persyaratan disolusi untuk sediaan tablet yang termasuk dalam kategori very rapidly dissolving adalah tidak boleh kurang dari 85\% zat aktif terdisolusi dalam waktu 15 menit. Hasil ujidisolusi pada Tabel II menunjukkan bahwa semua formula pada menit ke-15 sudah terdisolusi lebih dari 85\% sehingga memenuhi persyaratan uji disolusi yang ditetapkan. Grafik SLD respon uji disolusi yang ditampilkan pada Gambar 1 menunjukkan pola quadratic dengan garis yang melengkung ke bawah sehingga dapat diartikan bahwa terdapat interaksi antara CP dan CCS yang menyebabkan penurunan disolusi obat. Hal yang sama juga ditunjukkan dari persamaan simplex lattice design respon disolusi. Persamaan simplex lattice design yang diperoleh untuk respon disolusi adalah $\mathrm{Y}=12,97(\mathrm{~A})+13,20(\mathrm{~B})-0,30(\mathrm{~A})(\mathrm{B})$. Persamaan ini menunjukkan bahwa interaksi keduanya memberikan pengaruh negatif terhadap disolusi obat dengan nilai koefisien $-0,30$. 
Penentuan formula optimum dilakukan dengan menggunakan software Design Expert ${ }^{\circledR}$ version 9.0.3.1 (trial). Goal, batas bawah dan batas atas serta importance dari parameter sifat fisik tablet (kekerasan, kerapuhan, waktu disintegrasi, waktu pembasahan) dan disolusi ditunjukkan pada tabel IV.

Grafik contour plot hasil optimasi untuk prediksi formula optimum berdasarkan parameter-parameter yang ditentukan disajikan pada Gambar 2. Formula optimum dipilih yang memiliki nilai desirability tertinggi. Gambar 2 memberikan informasi bahwa titik optimum ditunjukkan pada formula dengan kombinasi superdisintegrant CP-CCS 6:1 dengan nilai desirability 0,858 .

\section{KESIMPULAN}

Kombinasi kadar superdisintegrant $\mathrm{CP}$ CCS berpengaruh terhadap sifat fisik FDT HCT. Hasil penelitian menunjukkan bahwa CP berpengaruh signifikan dalam mempercepat waktu pembasahan, waktu disintegrasi, dan disolusi tablet, sedangkan CCS berpengaruh signifikan dalam menurunkan kekerasan, meningkatkan kerapuhan dan rasio absorpsi air. Komposisi formula optimum FDT HCT terdiri dari kombinasi superdisintegrant dengan perbandingan CP 6\%-CCS 1\% terhadap bobot tablet.

\section{DAFTAR PUSTAKA}

Allen, L.V., Popovich, N.G., \& Ansel, H.C., 2011, Ansel's Pharmaceutical Dosage Forms and Drug Delivery Systems, 9th Ed., 228,233, Lippincott Williams \& Wilkins, Philadelphia.

Battu, S.K., Repka, M.A., Majumdar, S., \& Madhusudan, R.Y., 2007, Formulation and Evaluation of Rapidly Disintegrating Fenoverine Tablets: Effect of Superdisintegrants, Drug Development and Industrial Pharmacy, 33 (11), 12251232.

Bhowmik, D., Krishnakanth, C.B., Pankaj., \& Chandira, R.M., 2009, Fast Dissolving Tablet : An Overview, Journal of Chemical and Pharmaceutical Research, 1 (1), 163177.

Departemen Kesehatan RI, 2006, Pharmaceutical Care Untuk Penyakit Hipertensi, 13,37,42, Departemen Kesehatan Republik Indonesia, Jakarta.
Department of Health, 2014, British Pharmacopoiea, Vol. III, 75, Appendix XII B, 345, The Departement of Health, London.

Fu, Y., Yang S., Jeong, S. H., Kimura, S., \& Park, K., 2004, Orally Fast Disintegrating Tablets: Developments, Technologies, TasteMasking and Clinical Studies, Critical Review in Therapeutic Drug Carrier System, 21 (6), 433-475.

Gohel, M.C., Parikh, R.K., Brahmbhatt, B.K., \& Shah, A.R., 2007, Improving the Tablet Characteristic and Dissolution Profile of Ibuprofen by Using a Novel Coprocessed Superdisintegrant: A Technical Note, AAPS Pharm. Sci. Tech., 8 (1), 1-6.

Guest, R.T., 2009, Croscarmellose Sodium, dalam Rowe, R.C., Sheskey P.J., \& Quin, M.E., (Eds.), Handbook of Pharmaceutical Excipients, $6^{\text {th }}$ Ed., 206-208, Pharmaceuticals Press, Washington D.C.

Moffat, A.C., Osselton, M.D., \& Widdop, B., (Eds.), 2011, Clarke's Analysis of Drugs and Poisons, $\quad 4^{\text {th }} \quad$ Ed., $1493-1494$, Pharmaceutical Press, London.

Nugroho, A.E., 2012, Farmakologi: Obat-obat Penting dalam Dunia Pendidikan dan Kesehatan, Cetakan I, 103,107,111, Pustaka Pelajar, Yogyakarta.

Schiermeier, S. dan Schmidt, P.C., 2002, Fast Dispersible Ibuprofen Tablets, European Journal of Pharmaceutical Sciences, 15 (3), 295-305.

Soebagyo, S.S., Fudholi, A., Sulaiman, T.N.S., \& Kuswahyuning, R., 2013, Petunjuk Praktikum Teknologi dan Formulasi Sediaan Padat, Laboratorium Teknologi Farmasi Bagian Farmasetika Fakultas Farmasi Universitas Gadjah Mada, Yogyakarta.

Sulaiman, T.N.S., 2007, Teknologi dan Formulasi Sediaan Tablet, Cetakan I, 95103,128,200, Pustaka Laboratorium Teknologi Farmasi Fakultas Farmasi Universitas Gadjah Mada, Yogyakarta.

Vaghela, B.J., Kayastha, R.R., Bhatt, N.M., Pathak, N.L., Chudasama, A.H., \& Darediya, A.A., 2011, Formulation and Evaluation of Fast Disintegrating Tablet of Diclofenac Sodium, International Journal of Pharmaceutical Research and Development, 3 (6), 17-22.

World Health Organization, Proposal to Waive in 
Dewi Farahiyah, et al

vivo Bioequivalence Requirements for The WHO Model List of Essential Medicines Immediate Release: Solid Oral Dosage Forms Geneva, October 2005.

Zhang, Y., Wrzesinski, A., Moses, M., \& Bertrand, H., 2010, Comparison of Superdisintegrants in Orally
Disintegrating Tablets, Pharmaceutical Technology, 54-61.

Zhao, Na. dan Augsburger, L.L., 2005, Functionality Comparison of 3 Classes of Superdisintegrants in Promoting Aspirin Tablet Disintegration and Dissolution, AAPS Pharm. Sci. Tech., 6 (4), 634-640. 